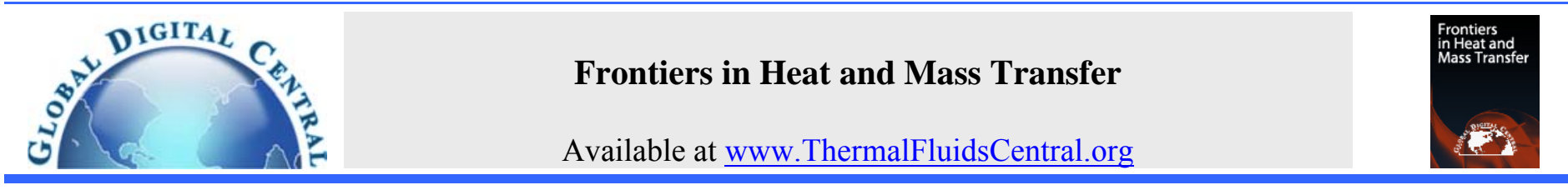

\title{
MODELING OF FREE CONVECTION HEAT TRANSFER UTILIZING NANOFLUID INSIDE A WAVY ENCLOSURE WITH A PAIR OF HOT AND COLD CYLINDERS
}

\author{
Zoubair Boulahia*, Abderrahim Wakif, Rachid Sehaqui \\ Hassan II University, Faculty of Sciences Aïn Chock, Laboratory of Mechanics, BP 5366 Maarif, 20100 Casablanca, Morocco
}

\begin{abstract}
In the present work, natural convection heat transfer of $\mathrm{Cu}$-water nanofluid inside a wavy wall enclosure is investigated numerically by using the finite volume discretization method. The study examines the effect of the nanoparticle volume fraction, the Rayleigh number, the wave amplitude, and the undulations number on the heat transfer rate. The results show that the heat transfer rate inside the wavy enclosure enhances by decreasing the wavy surface amplitude and increasing undulations number. It is also found that by increasing the volume fraction of nanoparticles and Rayleigh number, the heat transfer rate increases.
\end{abstract}

Keywords: Wavy Enclosure, Natural Convection, Nanofluid, Undulation, amplitude, circular Cylinder

\section{INTRODUCTION}

Natural convection fluid flow and heat transfer inside a wavy enclosure is found in many engineering applications, such as industrial heat radiators, heat exchanger design, cooling of micro-electronic devices, solar collector, and double-wall thermal insulation. The heat transfer inside a wavy enclosure has not been investigated widely due to the complexity of the geometry. Natural convection in a wavy enclosures show enhanced heat transfer when compared to the corresponding enclosure with flat walls (Abu-Nada and Oztop, (2011)). Thus, the study of fluid flow and heat transfer within wavy-walled enclosures is useful for many engineering problems related to geometrical design requirements. One of the first works on the numerical simulation of natural convection inside cavities is the pioneering work of De Vahl Davis, (1983). He performed a numerical simulation on a square cavity with two vertical isothermal walls, one cold and one hot, and two horizontal adiabatic walls. This cavity with those boundary conditions is known as differentially heated cavity (DHC). Boulahia et al., (2016) studied natural convection heat transfer of the nanofluids in a square enclosure with an inside cold obstacle. The results show that the heat transfer rate inside the enclosure increases by increasing the height of the cold block, the volume fraction of nanoparticles and Rayleigh number. Other examples can be found in references (Boulahia et al., (2016); Boulahia and Sehaqui, (2015); Boulahia et al., (2016) and Boulahia et al., (2016)). Abu-Nada and Oztop, (2011) analyzed heat transfer enhancement of $\mathrm{Al}_{2} \mathrm{O}_{3}$-water nanofluids in natural convection applied to differentially heated wavy cavities. Oztop et al., (2011) analyzed the effects of volumetric heat sources on natural convection heat transfer and flow structures in a wavy-walled enclosure. They found that the function of wavy wall and the ratio of internal Rayleigh number to external Rayleigh number affect the heat transfer and fluid flow significantly. Work of Mahmud and Fraser, (2007) was concentrated on buoyancydriven flow inside a cavity with two horizontal straight walls and two vertical wavy walls. Then, their geometry was extended to examine the heat transfer characteristics using the heat-lines visualization technique described by Mahmud and Fraser, (2004). Moreover, Mahmud and Islam, (2003) investigated entropy generation in wavy enclosures numerically. Abdelkader et al., (2007) studied the single wavy-walled cavity with small amplitude of the wavy wall. Khanafer et al., (2009) made a numerical analysis on natural convection inside a cavity with a sinusoidal vertical wavy wall and filled with a porous medium. They used the finite-element formulation based on the Galerkin method to solve governing equations. Sultana and Hyder, (2007) investigated the non-Darcy free convection in a wavy enclosure consisting of two isothermal wavy walls using the finite-element method. Varol and Oztop, (2006) analyzed the natural convection in a wavy bottom walled shallow enclosure without internal heat generation. They found that the heat transfer was increased with decreasing values of the non-dimensional wave length whereas it increased with increasing values of the aspect ratio and the Rayleigh number. Other examples can be found in reference Das and Mahmud, (2003).

The aim of this study is to explore the heat transfer rate of natural convection heat transfer of nanofluid (Cu-water) in a wavy-wall enclosure. The first case under investigation is characterized the numerical models used in our study. The computational procedure elaborated in this study is validated against the numerical results of other investigations. We studied the effects wave amplitude a (from 0.05 to 0.2 ) and undulations number (from 1 to 3 ) on the heat transfer rate. Wide range of parameters such as Rayleigh number $\left(10^{3} \leq R a \leq 10^{6}\right)$, and volume fraction of nanoparticles $(0 \leq \varphi \leq 0.05)$ have been used. The new models of the thermal conductivity and effective viscosity investigated by Corcione, (2011) are used to estimate themophysical proprieties of the nanofluid. Our numerical results are presented in the form of plots of isotherms, streamlines and average Nusselt numbers to show the influence of nanofluid and pertinent parameters. 


\section{PROBLEM STATEMENT}

The studied configurations and coordinate system of the considered wavy enclosure in the present study are shown in Fig. 1. Two cases are considered, Case 1 is a square cavity with top and bottom wavy surface for the height of $H$ while the vertical walls are maintained respectively at hot $T_{h}$ and cold $T_{c}$ temperatures; the other walls are adiabatic. On the other hand, Case 2 shows a wavy enclosure with a pair of hot and cold circular cylinders with radius equal to $0.1 \mathrm{H}$ while the vertical walls are heated. It is assumed that the nanofluid is newtonian, incompressible and laminar $\left(R a \leq 10^{6}\right)$ and the base fluid and the nanoparticles are in a thermal equilibrium state. The thermo-physical properties of the nanofluid used in this study are evaluated at the average fluid temperature $\left(T_{c}+T_{h}\right) / 2$ as listed in Table 1.
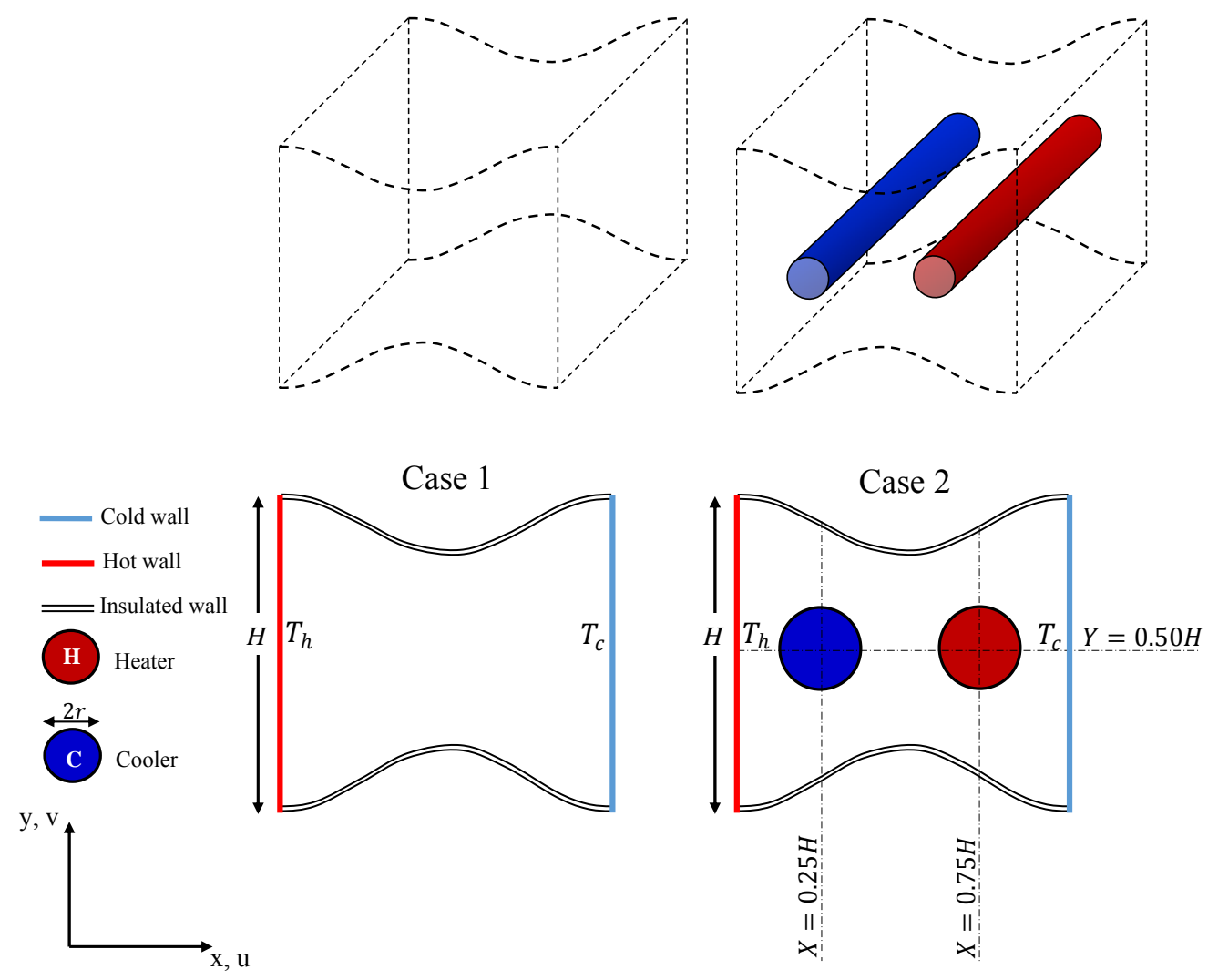

Fig. 1 Schematic of the wavy cavity for two different cases and boundary conditions.

Table 1 Thermo-physical properties of water and nanoparticles at $\mathrm{T}=$ $300 \mathrm{~K}$ Incropera and De Witt, (2002)

\begin{tabular}{lll}
\hline & Copper $(\mathrm{Cu})$ & Water $\left(\mathrm{H}_{2} \mathrm{O}\right)$ \\
\hline$C_{p}(\mathrm{~J} / \mathrm{Kg} \mathrm{K})$ & 385 & 4179 \\
$\rho\left(\mathrm{Kg} / \mathrm{m}^{3}\right)$ & 8933 & 997.1 \\
$k(\mathrm{~W} / \mathrm{mK})$ & 401 & 0.6 \\
$\beta\left(\mathrm{K}^{-1}\right)$ & $1.6710^{-5}$ & $27.610^{-5}$ \\
$\mu\left(\mathrm{kg} \mathrm{m}^{-1} \mathrm{~s}^{-1}\right)$ & - & $0.85510^{-3}$ \\
\hline
\end{tabular}

\section{MATHEMATICAL FORMULATION}

The governing equations including the two-dimensional transient equations of the continuity, momentum and energy for an incompressible flow are expressed in the following format:

$$
\begin{aligned}
\frac{\partial u}{\partial x}+\frac{\partial v}{\partial y}=0 & \begin{aligned}
\frac{\partial u}{\partial t}+u \frac{\partial u}{\partial x}+v \frac{\partial u}{\partial y}= & -\frac{1}{\rho_{n f}} \frac{\partial p}{\partial x}+\frac{\mu_{n f}}{\rho_{n f}}\left(\frac{\partial^{2} u}{\partial x^{2}}+\frac{\partial^{2} u}{\partial y^{2}}\right) \\
\frac{\partial v}{\partial t}+u \frac{\partial v}{\partial x}+v \frac{\partial v}{\partial y}= & -\frac{1}{\rho_{n f}} \frac{\partial p}{\partial y}+\frac{\mu_{n f}}{\rho_{n f}}\left(\frac{\partial^{2} v}{\partial x^{2}}+\frac{\partial^{2} v}{\partial y^{2}}\right) \\
& +\frac{(\rho \beta)_{n f}}{\rho_{n f}}\left(T-T_{c}\right)
\end{aligned}
\end{aligned}
$$

$$
\frac{\partial T}{\partial t}+u \frac{\partial T}{\partial x}+v \frac{\partial T}{\partial y}=\alpha_{n f}\left(\frac{\partial^{2} T}{\partial x^{2}}+\frac{\partial^{2} T}{\partial y^{2}}\right)
$$

where the nanofluid effective density, heat capacity, thermal expansion coefficient and thermal diffusivity are calculated from the following equations (Corcione, (2010) and Haddad et al., (2012)):

$$
\begin{aligned}
& \rho_{n f}=(1-\varphi) \rho_{f}+\varphi \rho_{s} \\
& \left(\rho C_{p}\right)_{n f}=(1-\varphi)\left(\rho C_{p}\right)_{f}+\varphi\left(\rho C_{p}\right)_{s} \\
& (\rho \beta)_{n f}=(1-\varphi)(\rho \beta)_{f}+\varphi(\rho \beta)_{s} \\
& \alpha_{n f}=k_{n f} /\left(\rho C_{p}\right)_{n f}
\end{aligned}
$$

Corcione model (Corcione, (2010) and Corcione, (2011)) for dynamic viscosity and thermal conductivity of the nanofluid are given by:

$$
\begin{aligned}
& \mu_{n f}=\mu_{f} /\left(1-34.87\left(d_{p} / d_{f}\right)^{-0.3} \varphi^{1.03}\right) \\
& \frac{k_{n f}}{k_{f}}=1+4.4 \operatorname{Re}_{B}^{0.4} \operatorname{Pr}^{0.66}\left(\frac{T}{T_{f r}}\right)^{10}\left(\frac{k_{p}}{k_{f}}\right)^{0.03} \varphi^{0.66} \\
& \operatorname{Re}_{B}=\frac{\rho_{f} u_{B} d_{p}}{\mu_{f}} \\
& u_{B}=\frac{2 k_{b} T}{\pi \mu_{f} d_{p}^{2}}
\end{aligned}
$$


The boundary conditions for mixed convection written as:

$$
\begin{array}{lll}
u=0, & v=0, \quad \partial T / \partial y=0 & \text { at } y=0 \text { and } 0 \leq x \leq H \\
u=0 & v=0, \quad \partial T / \partial y=0 & \text { at } y=H \text { and } 0 \leq x \leq H \\
u=0, \quad v=0, \quad T=T_{c} & \text { at } x=H \text { and } 0 \leq y \leq H \\
u=0, \quad v=0, T=T_{h} & \text { at } x=0 \text { and } 0 \leq y \leq H
\end{array}
$$

The following dimensionless variables for Natural convection are defined based on properties of pure fluid:

$$
\begin{aligned}
& \tau=\frac{t}{\frac{H}{U_{\text {ref }}}}, \quad X=\frac{x}{H}, \quad Y=\frac{y}{H}, \quad U=\frac{u}{U_{\text {ref }}}, \\
& V=\frac{v}{U_{\text {ref }}}, \quad P=\frac{p}{\rho_{\text {nf }} U_{\text {ref }}^{2}}, \quad \theta=\frac{T-T_{c}}{T_{h}-T_{c}},
\end{aligned}
$$

where $U_{\text {ref }}$ is considered to be $\alpha_{f} / H$ for natural convection. Dimensionless numbers for the system are defined as:

$$
\begin{aligned}
& G r=\frac{g \beta_{f}\left(T_{h}-T_{c}\right) H^{3}}{v_{f}^{2}}, \quad R a=G r \cdot P r \\
& R a=G r \cdot P r=\frac{g \beta_{f}\left(T_{h}-T_{c}\right) H^{3}}{\alpha_{f} v_{f}}, \quad P r=\frac{v_{f}}{\alpha_{f}},
\end{aligned}
$$

The governing equations (1)-(4) are written in the following dimensionless form:

$$
\begin{aligned}
& \frac{\partial U}{\partial X}+\frac{\partial V}{\partial Y}=0 \\
& \frac{\partial U}{\partial \tau}+U \frac{\partial U}{\partial X}+V \frac{\partial U}{\partial Y}=-\frac{\partial P}{\partial X}+\operatorname{Pr} \frac{\rho_{f}}{\rho_{n f}} \frac{\mu_{n f}}{\mu_{f}}\left(\frac{\partial^{2} U}{\partial X^{2}}+\frac{\partial^{2} U}{\partial Y^{2}}\right) \\
& \frac{\partial V}{\partial \tau}+U \frac{\partial V}{\partial X}+V \frac{\partial V}{\partial Y}=-\frac{\partial P}{\partial Y}+\operatorname{Pr} \frac{\rho_{f}}{\rho_{n f}} \frac{\mu_{n f}}{\mu_{f}}\left(\frac{\partial^{2} V}{\partial X^{2}}+\frac{\partial^{2} V}{\partial Y^{2}}\right) \\
& +R a \cdot \operatorname{Pr} \frac{(\rho \beta)_{n f}}{\rho_{n f} \beta_{f}} \theta \\
& \frac{\partial \theta}{\partial \tau}+U \frac{\partial \theta}{\partial X}+V \frac{\partial \theta}{\partial Y}=\frac{\alpha_{n f}}{\alpha_{f}}\left(\frac{\partial^{2} \theta}{\partial X^{2}}+\frac{\partial^{2} \theta}{\partial Y^{2}}\right)
\end{aligned}
$$

Dimensionless form of the boundary conditions can be written as:

$$
\begin{array}{lll}
U=0, \quad V=0, \quad \partial \theta / \partial Y=0 & \text { at } Y=0 \text { and } 0 \leq X \leq 1 \\
U=0, \quad V=0, \quad \partial \theta / \partial Y=0 & \text { at } Y=1 \text { and } 0 \leq X \leq 1 \\
U=0, \quad V=0, \theta=0 & \text { at } X=1 \text { and } 0 \leq Y \leq 1 \\
U=0, \quad V=0, \theta=1 & \text { at } X=0 \text { and } 0 \leq Y \leq 1
\end{array}
$$

The shape of the wavy walls is described by the following equation:

$$
\begin{array}{ll}
Y=a[1-\cos (2 \pi \cdot n X)] & \text { at } Y=0 \text { and } 0 \leq X \leq 1 \\
Y=1+a[\cos (2 \pi \cdot n X)-1] & \text { at } Y=1 \text { and } 0 \leq X \leq 1
\end{array}
$$

where, (a) is the dimensionless height of the wave and (n) is the number of waves.

The dimensionless stream function can be written as:

$$
\psi=-\int_{Y_{O}}^{Y} U \partial Y+\psi\left(X, Y_{0}\right)
$$

where $\psi_{\max }=\max (\psi)$

The total mean Nusselt number of all cavity's wall is defined as:

$$
\overline{N u}_{\text {tot }}=\frac{1}{H} \int_{0}^{H} \frac{k_{n f}(\varphi)}{k}\left\{\left|\frac{\partial \theta}{\partial X}\right|_{\text {left }}+\left|\frac{\partial \theta}{\partial X}\right|_{\text {right }}\right\} d Y
$$

\section{NUMERICAL DETAILS}

The discretization procedure of the governing equations (Eqs. (17)-(20)) and boundary conditions described by Eq. (21) is based on a finite volume formulation, given by Patankar, (1980) is used to solve The vorticity, energy and the stream function equations while Hybrid Differencing Scheme (HDS) of Spalding, (1972) is used for the convective terms. Line by line application of TDMA (Tri-Diagonal Matrix Algorithm) method (Spalding, (1972)) is applied on equation systems until sum of the residuals became less than $10^{-6}$. The developed algorithm was implemented in FORTRAN program.

\subsection{Grid independence study}

In order to find a proper grid for the numerical simulation, a wavy enclosure filled by the $\mathrm{Cu}-$ water nanofluid $(\varphi=0.05)$ with a hot and cold circular cylinders, for $R=r / H=0.1$ and undulations number $\mathrm{n}=3$ is analyzed in two extreme Rayleigh numbers $\left(R a=10^{4}\right.$ and $\left.10^{6}\right)$. The mean Nusselt number obtained using different grid numbers for the case 2 of Fig. 1 is presented in Table 2. As can be observed from the table, a non-uniform $103 \times 103$ grid is sufficiently fine for the numerical calculation.

Table 2 Effect of the grid size on $\overline{N u}$ for the case 2 of Fig. 1. The enclosure filled by nanofluid $(\varphi=5 \%)$ with circular cylinders, for $R=$ 0.1 and undulations number $\mathrm{n}=3$.

\begin{tabular}{lllll}
\hline$R a$ & $63 \times 63$ & $83 \times 83$ & $103 \times 103$ & $123 \times 123$ \\
\hline $10^{4}$ & 6.978 & 7.061 & 7.140 & 7.143 \\
$10^{6}$ & 12.591 & 12.822 & 12.941 & 12.945 \\
\hline
\end{tabular}

\subsection{Validations}

The computational procedure was validated against various numerical results available in the literature, three different heat convection problems are chosen. The first case is the benchmark problem of natural convection in a square cavity which considered by De Vahl Davis, (1983) filled with Air $(\operatorname{Pr}=0.71)$. Table 3 demonstrates an excellent comparison of the average Nusselt number between the present results and the numerical results found in the literature (Barakos et al., (1994) -Dixit and Babu, (2006)). The second case is a natural convection heat transfer and flow structures in a wavy-walled enclosure. Fig. 2 illustrates a comparison of the isotherms and streamlines with the results reported by Oztop et al., (2011).

Table 3 Comparison of $\overline{N u}$ between the present results and those reported in the literature for a DHC at different Rayleigh numbers.

\begin{tabular}{lllll}
\hline$R a$ & $10^{3}$ & \multicolumn{1}{c}{$10^{4}$} & \multicolumn{1}{c}{$10^{5}$} & \multicolumn{1}{c}{$10^{6}$} \\
\hline $\begin{array}{l}\text { De Vahl Davis, (1983) } \\
\text { Relative Error (\%) }\end{array}$ & $\begin{array}{l}1.118 \\
0.17\end{array}$ & $\begin{array}{l}2.243 \\
0.13\end{array}$ & $\begin{array}{l}4.519 \\
0.75\end{array}$ & $\begin{array}{l}8.799 \\
0.54\end{array}$ \\
Barakos et al., (1994) & 1.114 & 2.245 & 4.510 & 8.806 \\
Relative Error (\%) & 0.17 & 0.22 & 0.55 & 0.62 \\
& & & & \\
Dixit and Babu, (2006) & 1.118 & 2.256 & 4.519 & 8.817 \\
Relative Error (\%) & 0.17 & 0.71 & 0.75 & 0.75 \\
& & & & \\
Present study & $\mathbf{1 . 1 1 6}$ & $\mathbf{2 . 2 4 0}$ & $\mathbf{4 . 4 8 5}$ & $\mathbf{8 . 7 5 1}$ \\
Grid size & $83^{2}$ & $83^{2}$ & $83^{2}$ & $103^{2}$ \\
\hline
\end{tabular}


(a)

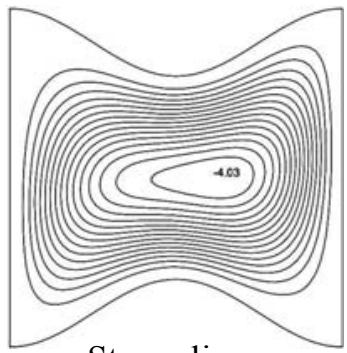

Streamlines

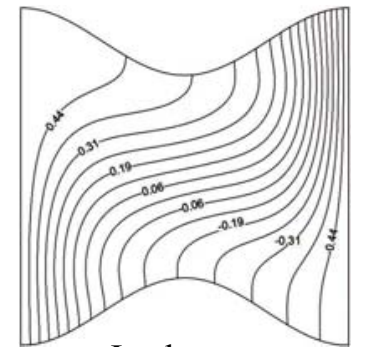

Isotherms
Oztop et al., (2011)

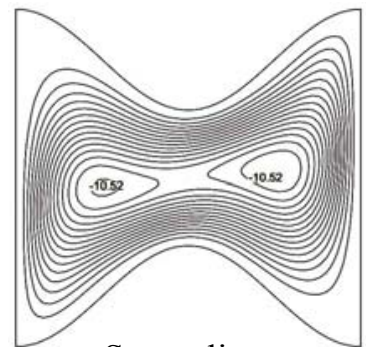

Streamlines (b)

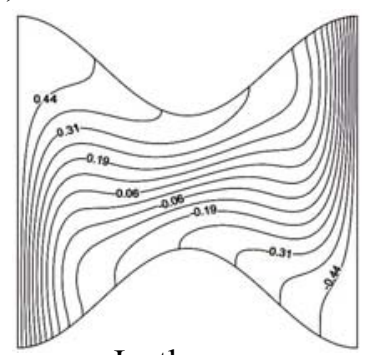

Isotherms (a)

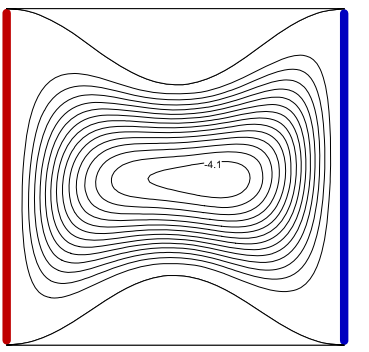

Streamlines

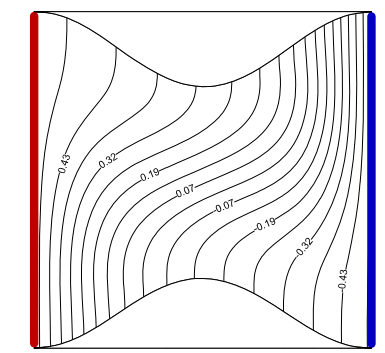

Isotherms

Present study

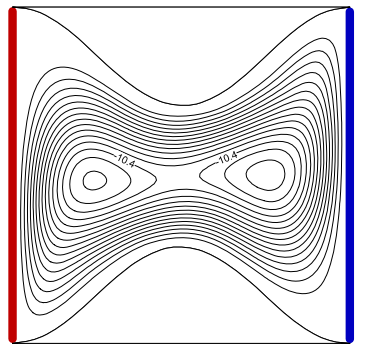

Streamlines (b)

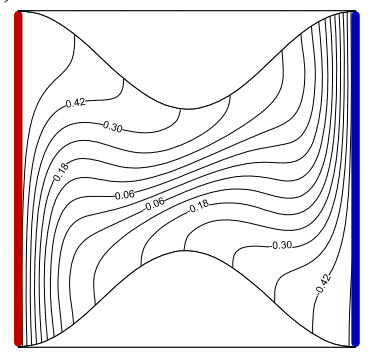

Isotherms

Fig. 2 Comparison of the isotherms and streamlines with that of Oztop et al., (2011) for $\operatorname{Pr}=0.7$. (a) $\mathrm{Rai}=\mathrm{Rae}=10^{4}, \mathrm{a}=0.9$, (b) Rai $=$ Rae $=10^{5}$, $\mathrm{a}=0.85$.

\section{RESULTS AND DISCUSSION}

In the present investigation, natural convection heat transfer of $\mathrm{Cu}$-water nanofluid inside a wavy enclosure is numerically simulated. The calculations are carried out in two phases. First, the effect of the amplitude of the wavy wall enclosure is studied. In the second phase, a wavy enclosure containing a pair of hot and cold circular cylinders with radius $(r=0.1 H)$ is considered, the results have been obtained for different undulations number. The numerical simulation results are presented in terms of streamlines, isotherms and average Nusselt number for various values of Rayleigh number and volume fraction of the nanoparticles.

\subsection{Effects of wavy surface amplitude}

In this section, the numerical results for natural convection heat transfer of $\mathrm{Cu}$-water nanofluid inside a wavy enclosure are discussed. Results pertinent to the effects of different values of wavy surface amplitude $(a=0.05,0.125$ and 0.2$)$, Rayleigh number $\left(10^{3} \leq R a \leq 10^{6}\right)$ and volume fraction of the nanoparticles $(0 \leq \varphi \leq 0.05)$.

Fig.3 (a-b) shows the effects of the wavy surface amplitude on the streamlines and isotherms for various values of $R$ a ranging from $10^{3}$ to $10^{6}$. To have a comparative look, the streamlines and the isotherms for pure fluid and nanofluid are shown by dashed line and solid line respectively. We can see in Fig. 3, some differences in streamlines and isotherms of pure fluid and nanofluid. We can explain this by the higher viscosity of nanofluid compared to that of the pure fluid which increases the diffusion of momentum in the nanofluid. As it is seen from the figure Fig. 3(a-b), both flow and temperature distributions are sensitive to wavy surface amplitude. we can see in Fig. 3(a) that increasing the value of amplitude reduce the fluid circulation within the wavy enclosure. At a smaller Rayleigh number, the flow field is characterized by a rotating eddy. By increasing the wavy surface amplitude from $\mathrm{a}=0.05$ to 0.2 we can see clearly that the rotating eddy became with two inner vortices. For all cases, the shape of the main cell changes with increasing of Rayleigh number. For small values of Rayleigh number, the induced flow has little intensity. Thus, the flow does not occupy the whole of the wavy enclosure. By increasing Rayleigh number, double circulation cells are formed where two small circulation bubbles are formed in the wavy enclosure. At $R a=10^{3}$ and $10^{4}$, the isotherms shown in Fig. 3(b) are uniformly distributed which indicate that the heat transfer in the cavity was governed mainly by the conduction mode. By increasing Rayleigh number from $10^{4}$ to $10^{6}$, it was observed in Fig. 3(b) that the patterns of isotherms became complex which means that the heat transfer mechanism is changing from conduction to the convection.

The mean temperature $\theta$, and mid-height vertical velocity component for various $X$ are displayed in Fig. 4(a-b-c). As shown in Fig. 4(a-c), increasing wavy surface amplitude and Rayleigh number devalues mean non-dimensional temperature. It can be seen from Fig. 4(c) that by increasing Rayleigh number, the curves become almost straight at the center. Fig. 4(b) shows that the mid height vertical velocity profile is perturbed appreciably for different values of wave amplitude. We can see clearly that the mid height $\mathrm{V}$ velocity component reduces for higher wavy surface amplitude $(a=0.2)$. We can explain this by the fact that the increase of viscous force leads to retardation in the velocity profile.

Fig. 5 shows values of $\psi_{\max }$ and $\overline{N u}$ at different Rayleigh number and volume fraction. The maximum stream function $\psi_{\max }$ shows in Fig. 5(a) decreases at all Rayleigh number by increasing volume fraction of nanoparticles, we can explain the decrease of $\psi_{\max }$ by Eq. (9) which indicates that the increasing volume fraction of the nanoparticles, leads to increase in the viscosity of the nanofluid. At high Rayleigh number $\left(R a \geq 10^{5}\right)$ there is an optimum volume fraction of nanoparticles which maximize the heat transfer is about $1 \%$ in the most cases. It is clear by increasing the Rayleigh number and decreasing the wavy surface amplitude, the rate of convective heat transfer is increased (see Fig. 5(b)). 

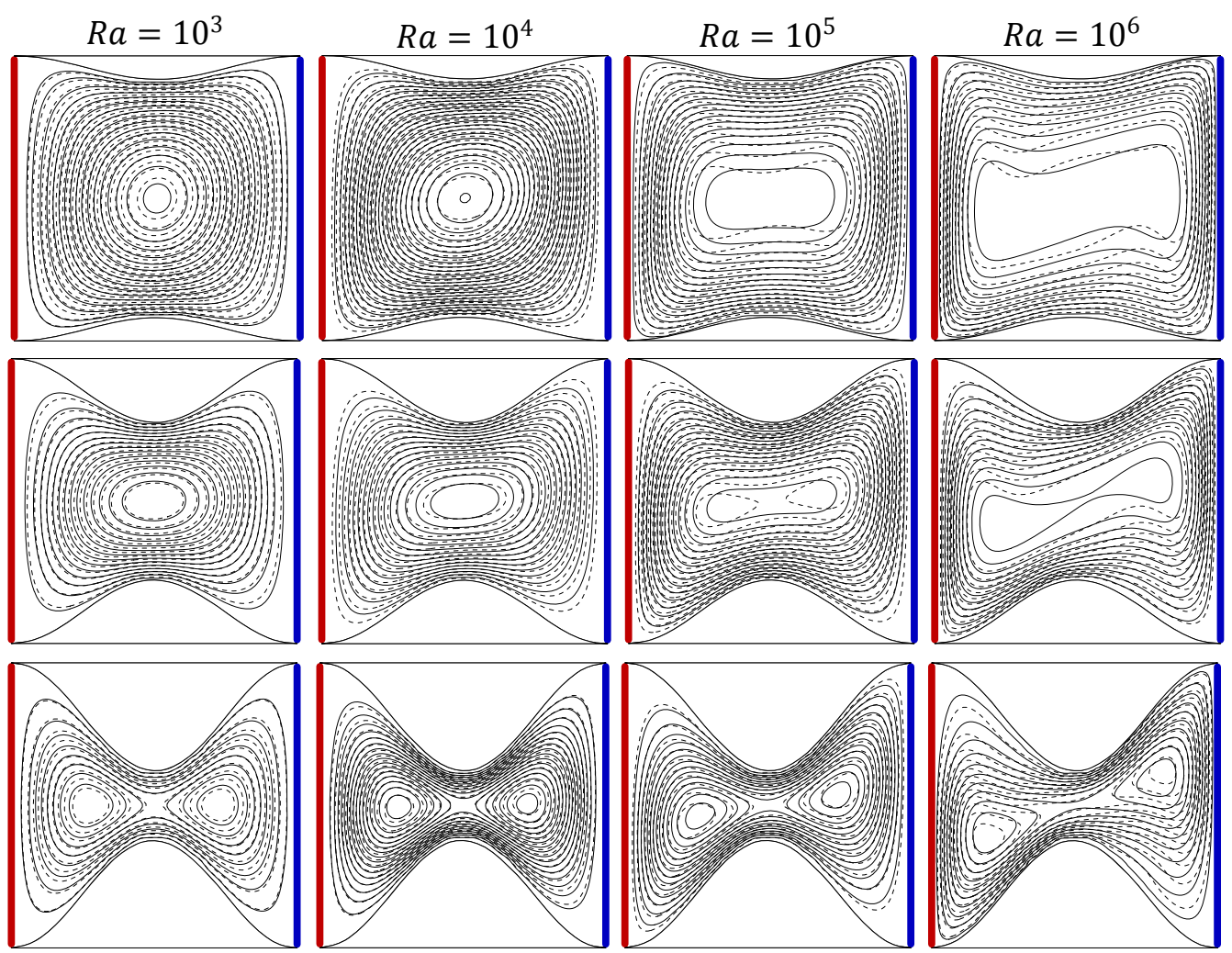

(a) streamlines
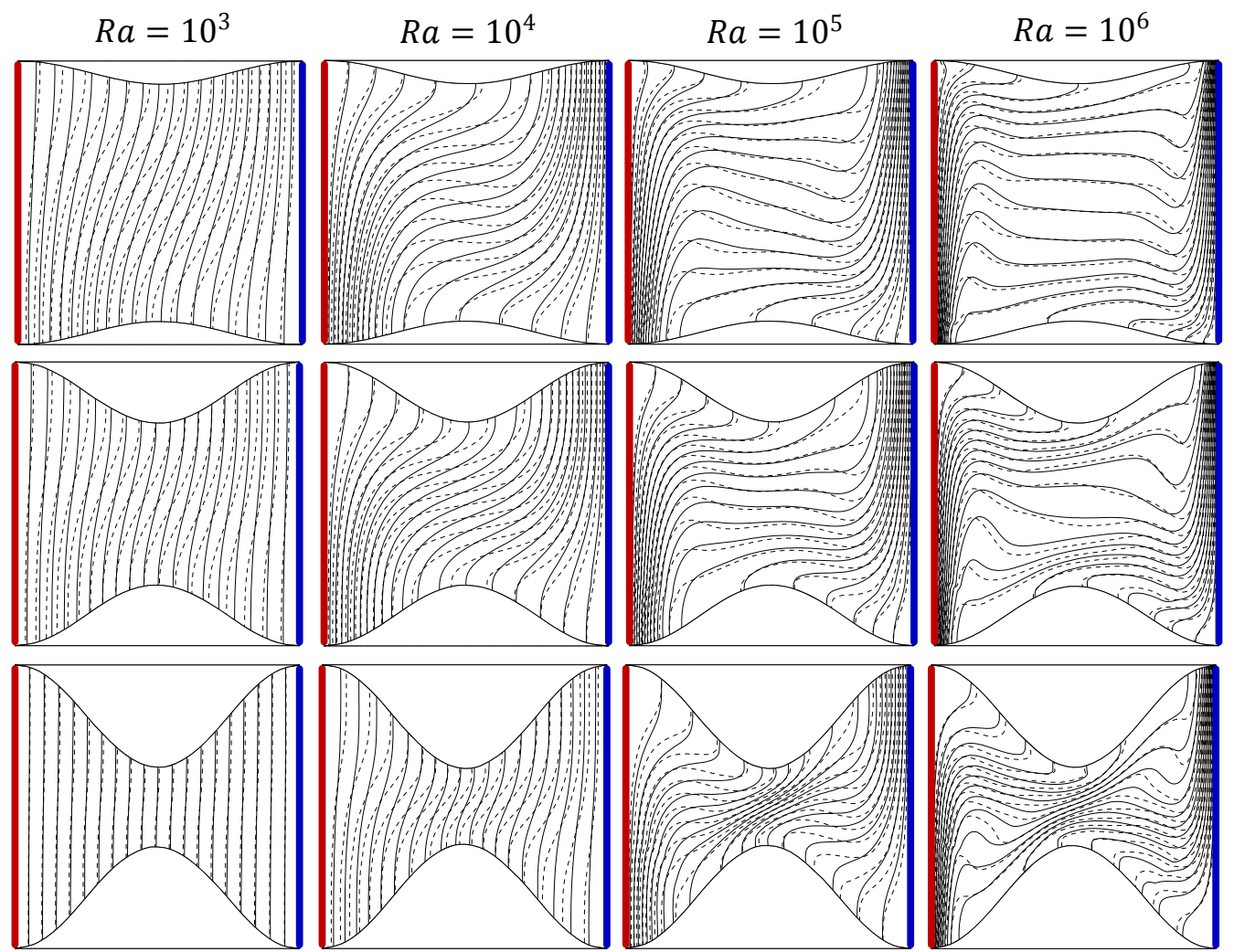

(b) isotherms

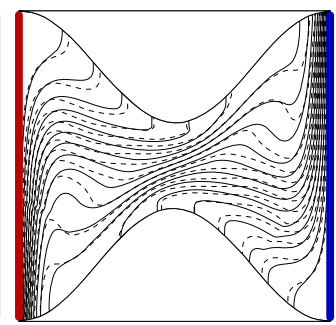

Fig. 3 (a) Streamlines and (b) isotherms inside the wavy enclosure corresponding to different values of wavy surface amplitude, i.e. a $=0.05,0.125$ and 0.2 filled with the pure fluid (dashed line) and $\mathrm{Cu}$-water nanofluid (solid line) with $\varphi=5 \%$ and at different Rayleigh numbers. 
(a)

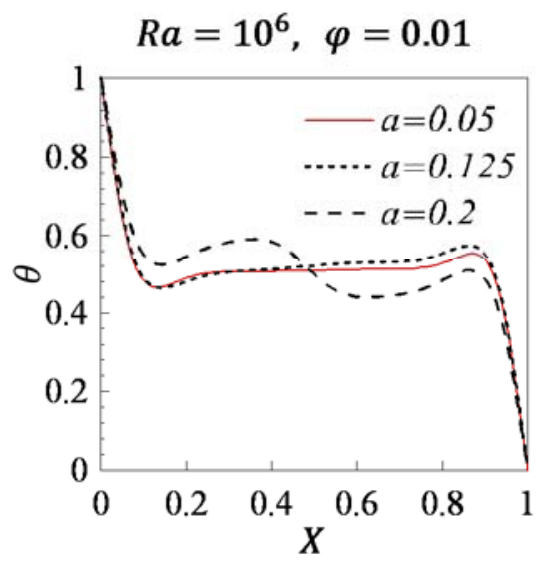

(b)

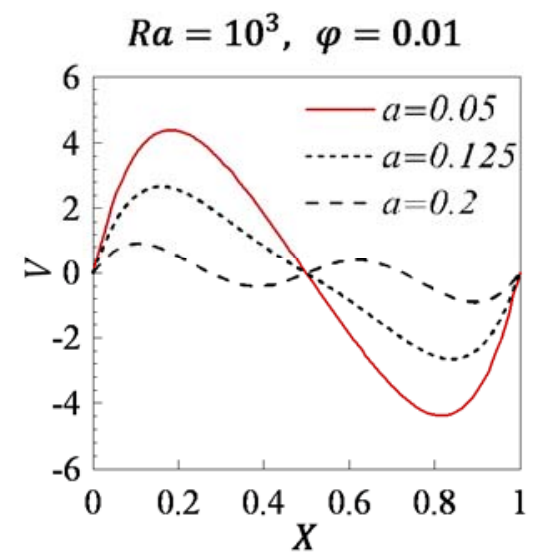

(c)

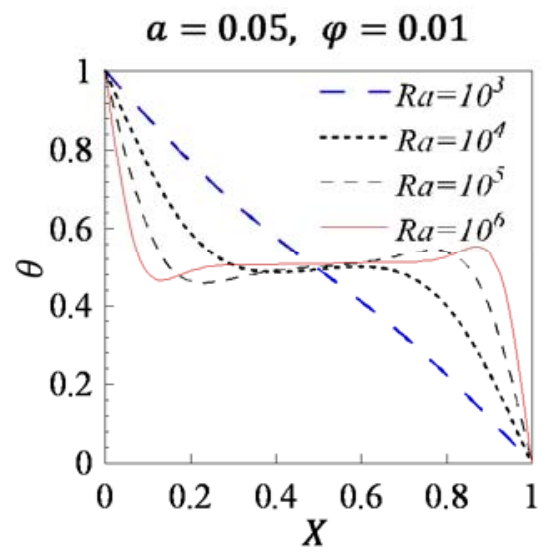

Fig. 4 (a) mean temperature $\theta$ and (b) mid-height V-velocity for different amplitude. (c) mean temperature $\theta$ for different Rayleigh numbers.

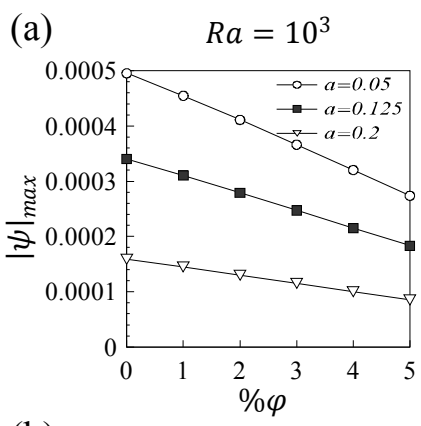

(b)

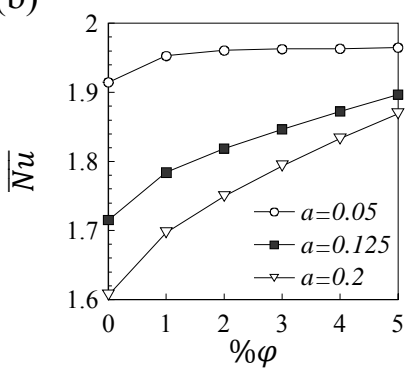

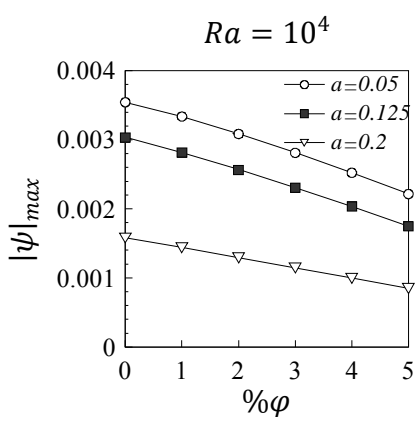

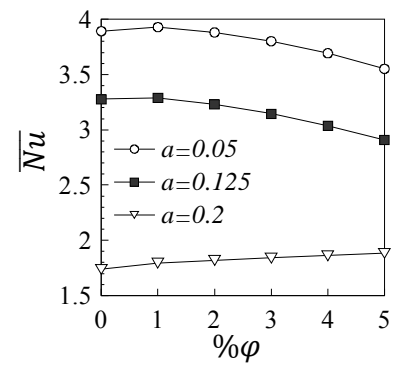

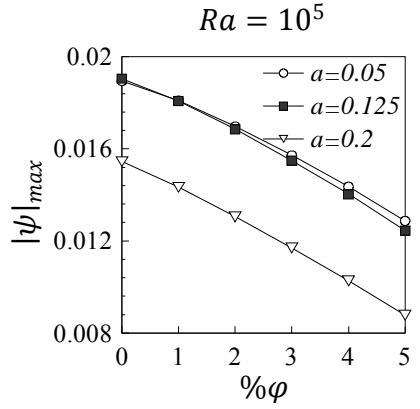

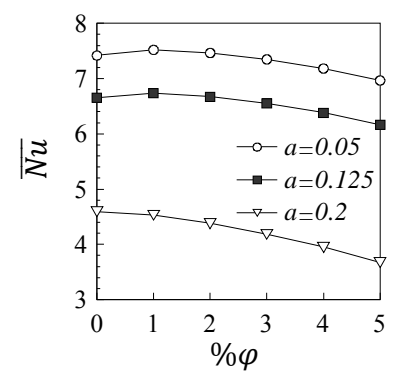

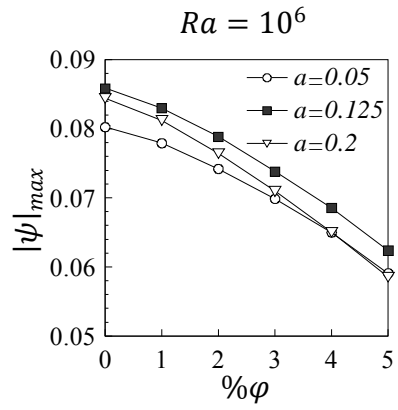

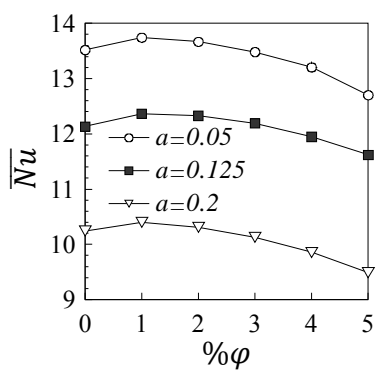

Fig.5. Variation of (a) $|\psi|_{\text {max }}$ and (b) $\bar{N} \bar{u}$ corresponding to different values of wavy surface amplitude, i.e. a $=0.05$, 0.125 and 0.2 for different Rayleigh numbers and volume fraction of the nanoparticles.

\subsection{Effects of undulation number}

In this section, natural convection heat transfer of $\mathrm{Cu}$-water nanofluid inside a wavy enclosure $(\mathrm{a}=0.1)$ with a pair of hot and cold circular cylinders with radius equal to $0.1 \mathrm{H}$ is studied. the effects of different values of undulation number $(n=1,2$, and 3$)$, Rayleigh number $\left(10^{3} \leq R a \leq 10^{6}\right)$ and volume fraction of the nanoparticles $(0 \leq \varphi \leq$ $0.05)$ on the heat transfer rate are investigated.

Fig. 6 (a-b) shows the effect of undulations number and pair circular heating and cooling bodies on the streamline and isotherms in different Rayleigh numbers. It can be seen from Fig. 6(a) that in $R a=10^{3}$ and $10^{4}$ a counterclockwise vortex forms inside the cavity between two circular bodies and four secondary vortexes appear near the enclosure corners, the vortexes of the upper left and lower right corners are more intense to those in the other corners. In Fig. 6(b) the uniformly distributed isotherms at this Rayleigh number shows that the main heat transfer mechanism is through the conduction. When $R a=10^{5}$ the intensity of the main vortex increases and becomes with two inner cores and the isotherms tightening around the circular body (Fig. 6b). By increasing Ra beyond $10^{5}$, the path of the fluid particles becomes more and more complex which indicates that the main heat transfer is changing from conduction to the convection. Also it can be observed that increasing the number of undulation (n) from 0 to 3 does not affect significantly the shape of streamlines except that near the wavy surfaces which takes nearly the shape of these surfaces.

Fig. 7(a-b) show clearly that these profiles are of boundary layer nature in the circular block. It can be seen from Fig. 7(a) that by increasing Rayleigh number, the mean temperature $\theta$ between the circular blocks is perturbed significantly. Fig.7(b) shows that the mid height vertical velocity profile between the circular blocks is changed appreciably for different values of undulations number.

Fig. 8 shows values of $\psi_{\max }$ and $\overline{N u}$ in the same conditions of Fig. 6 at different undulations number, volume fraction of nanoparticles and Rayleigh number. According to Fig. 8(b), it is noticed that by increasing volume fraction of nanoparticles and Rayleigh number the heat transfer rate increases. It is clear that the heat transfer rate enhances with increasing the undulations number from $n=1$ to 3 . We have seen that at small values of Rayleigh number, the conduction is significantly dominant therefore enhancement of heat transfer rate is maximum for $\varphi=5 \%$. At high Rayleigh number $\left(R a \geq 10^{5}\right)$ the effects of natural convection are dominant so there is an optimum volume fraction of nanoparticles which maximize the heat transfer is about $1 \%$ in the most cases. 

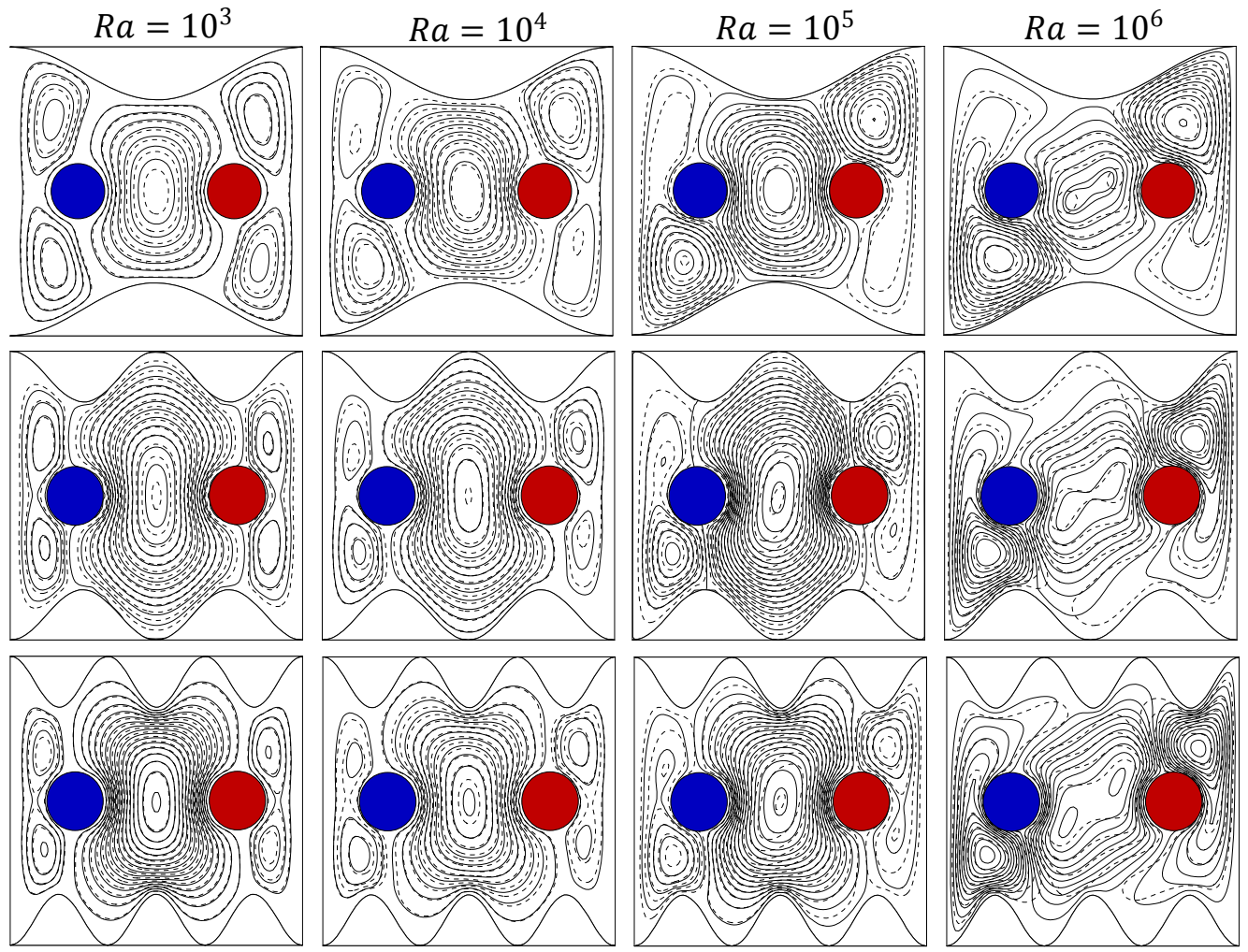

(a) streamlines
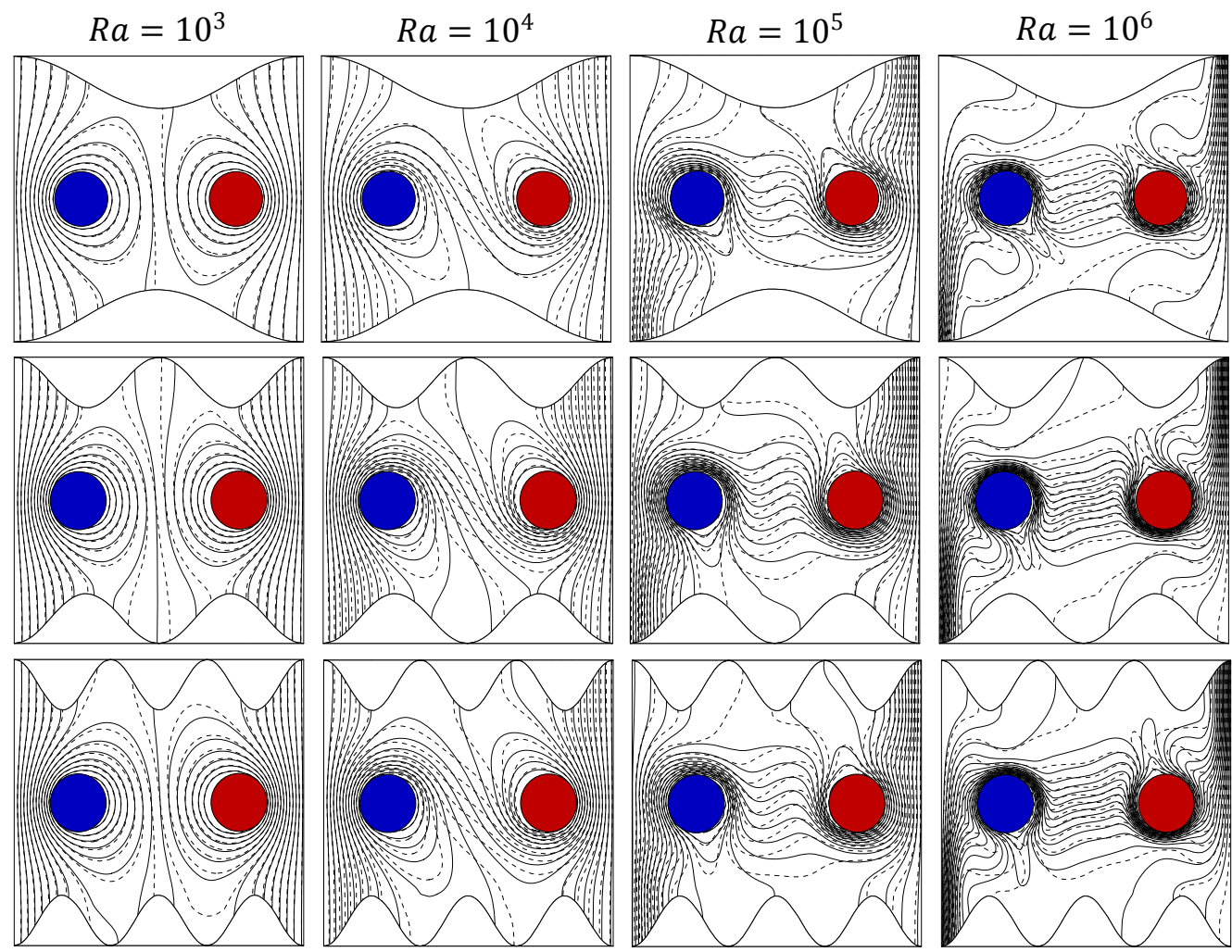

(b) isotherms

Fig.6 (a) Streamlines and (b) isotherms inside the wavy enclosure $(\mathrm{a}=0.1)$ with a pair of hot and cold circular cylinders $(R=r / H=0.1)$, corresponding to different values of undulations number, i.e. $\mathrm{n}=1,2$ and 3 filled with the pure fluid (dashed line) and $\mathrm{Cu}$-water nanofluid (solid line) with $\varphi=5 \%$ and at different Rayleigh numbers. 
(a)

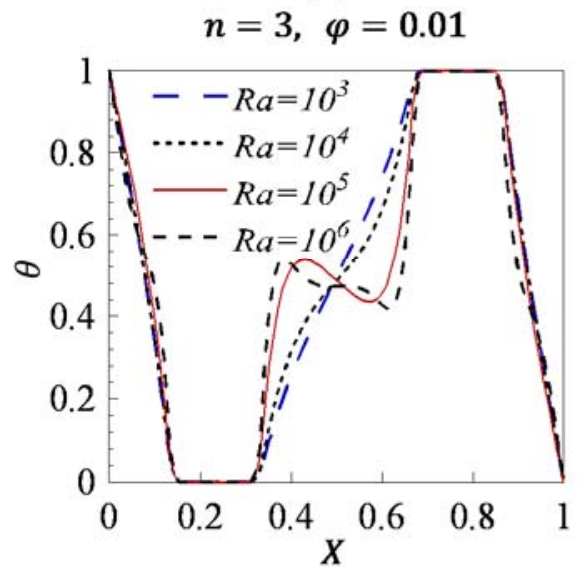

(b)

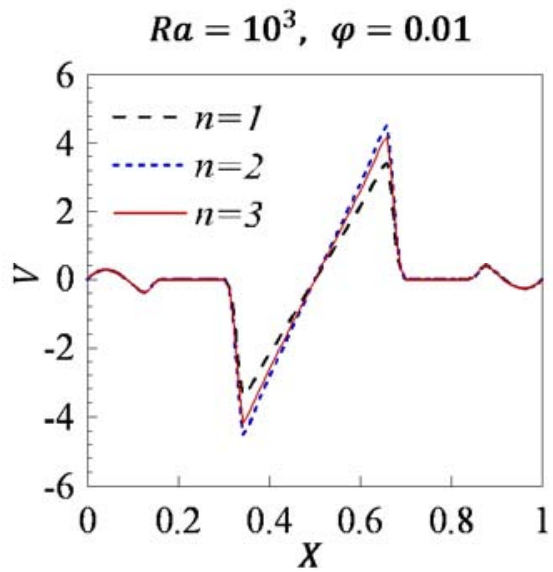

Fig.7 (a) mean temperature $\theta$ for different Rayleigh numbers and (b) mid-height $V$-velocity for different undulations number.

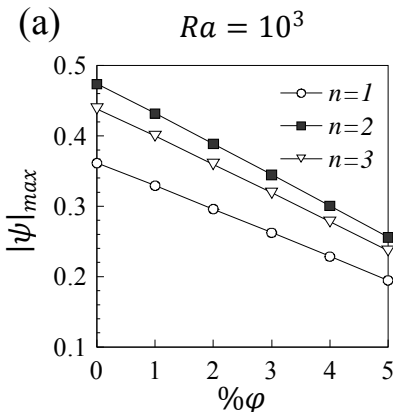

(b)

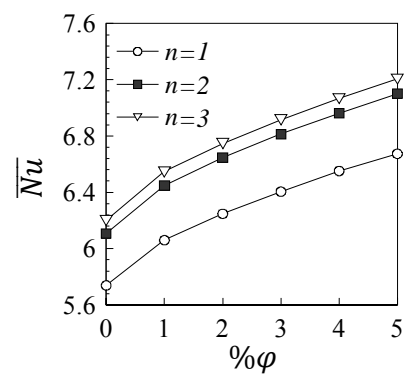

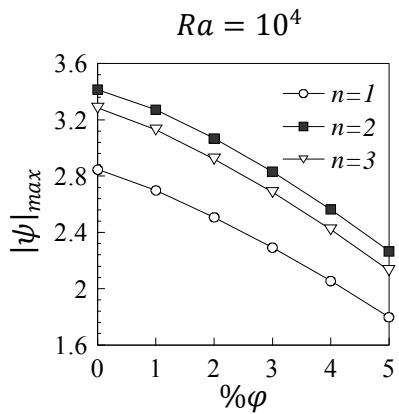

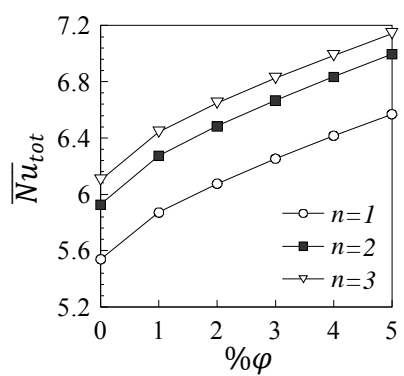

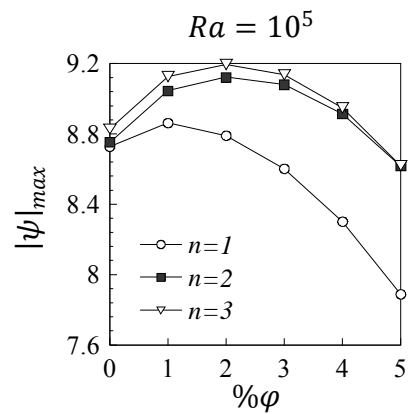
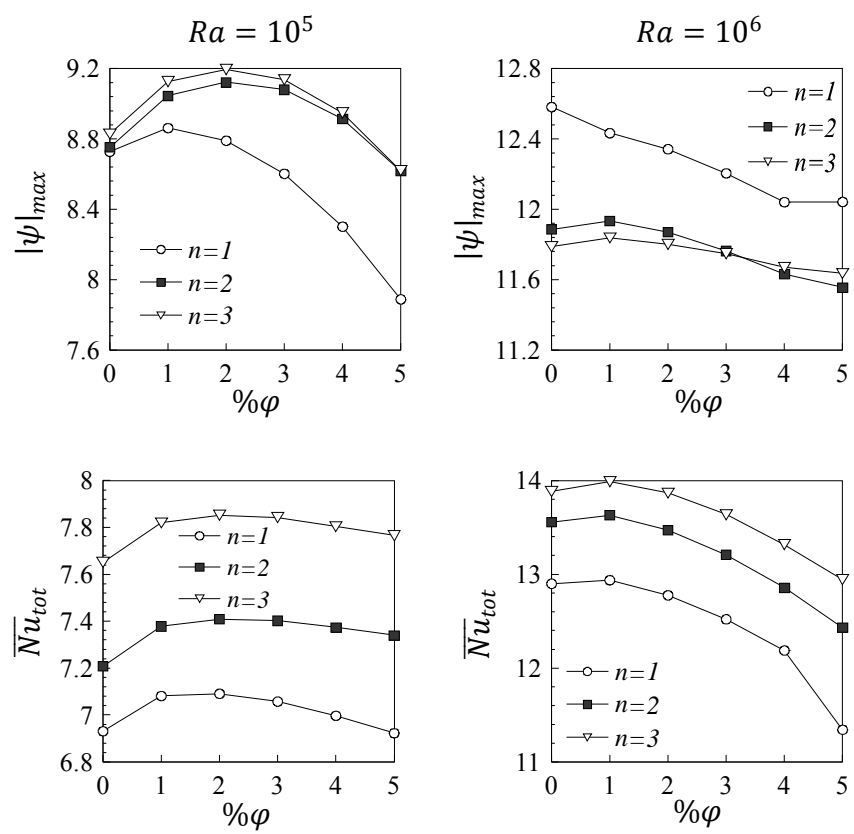

Fig.8 Variation of (a) $|\psi|_{\max }$ and (b) $\overline{N u}$ corresponding to different values of undulations number, i.e. $\mathrm{n}=1,2$ and 3 for different Rayleigh numbers and volume fraction of the nanoparticles.

\section{CONCLUSION}

The two-dimensional natural convection heat transfer of nanofluid in a square enclosure with top and bottom wavy surface have been simulated numerically. Effects of wavy surface amplitude, undulations number and hot and cold circular cylinders are investigated. The numerical simulation results are realized for various values of Rayleigh number $\left(10^{3} \leq R a \leq 10^{6}\right)$ and volume fraction of the nanoparticles $(0 \leq \varphi \leq$ $0.05)$. According to the presented results, the following conclusions are drawn:

i. At high Rayleigh number, there is an optimum volume fraction of nanoparticles which maximize the heat transfer is about $1 \%$ in the most cases.

ii. Increasing the wavy surface amplitude and Rayleigh number devalues mean non-dimensional temperature and the mid height $\mathrm{V}$ velocity component reduces for higher wavy surface amplitude $(a=0.2)$. iii. By increasing the Rayleigh number and decreasing the wavy surface amplitude, the rate of convective heat transfer is increased, the maximum values of mean Nusselt number are deduced for $\mathrm{a}=0.05$.

iv. By increasing Rayleigh number, the mean temperature $\theta$ between the circular blocks is perturbed significantly and the mid height vertical velocity profile between the circular blocks is changed appreciably for different values of undulations number.

v. At all Rayleigh number, the heat transfer rate enhances with increasing the undulations number from $n=1$ to 3 .

\section{ACKNOWLEDGMENTS}

The authors wish to express their very sincerely thanks to the reviewers for their valuable and lucid comments which have improved the paper appreciably. 


\section{NOMENCLATURE}

$C_{p} \quad$ specific heat, $\mathrm{Jkg}^{-1} \mathrm{~K}^{-1}$

$d_{p} \quad$ diameter of the nanoparticle, $m$

$d_{f} \quad$ diameter of the base fluid molecule, $m$

$g \quad$ gravitational acceleration, $\mathrm{ms}^{-2}$

Gr Grashof number $\left(=g \beta \Delta T H^{3} / v^{2}\right)$

$H \quad$ enclosure height, $\mathrm{m}$

$k \quad$ thermal conductivity, $W m^{-1} K^{-1}$

$k_{b} \quad$ Boltzmann's constant $=1.38066 \times 10^{-23}$

$N \quad$ Number of triangular heated blocks

$\bar{N} \bar{u}_{\text {tot }} \quad$ heat transfer of cavity's wall

$p \quad$ dimensional pressure, $\mathrm{Nm}^{-2}$

$P \quad$ dimensionless pressure

$\operatorname{Pr} \quad$ Prandtl number $\left(=v_{f} / \alpha_{f}\right)$

$R a \quad$ Rayleigh number $\left(=g \beta_{f}\left(T_{h}-T_{c}\right) H^{3} / \alpha_{f} v_{f}\right)$

$\operatorname{Re}_{B} \quad$ Brownian-motion Reynolds number

$T \quad$ temperature, $K$

$t \quad$ time, $\mathrm{s}$

$\tau \quad$ dimensionless time $\left(t / H / U_{\text {ref }}\right)$

$u, v \quad$ velocity components, $m s^{-1}$

$u_{B} \quad$ Brownian velocity of the nanoparticle, $m s^{-1}$

$U, V \quad$ dimensionless velocity components

$w \quad$ dimensional size of the cylinder

$W \quad$ dimensionless size of the cylinder

$x, y \quad$ Cartesian coordinates, $m$

$X, Y \quad$ dimensionless Cartesian coordinates $(x, y) / H$

Greek symbols

$\begin{array}{ll}\alpha & \text { thermal diffusivity, } \mathrm{m}^{2} \mathrm{~s}^{-1} \\ \beta & \text { thermal expansion coefficient, } K^{-1} \\ \theta & \text { dimensionless temperature } \\ \mu & \text { dynamic viscosity, } \mathrm{kg} \mathrm{m}^{-1} \mathrm{~s}^{-1} \\ \nu & \text { kinematic viscosity, } \mathrm{m}^{2} \mathrm{~s}^{-1} \\ \rho & \text { density, } \mathrm{kgm}^{-3} \\ \varphi & \text { volume fraction of the nanoparticles } \\ \psi & \text { stream function }\left(=-\int_{Y_{o}}^{Y} U \partial Y+\psi\left(X, Y_{0}\right)\right)\end{array}$

Subscripts

c cold

$f \quad$ fluid

$h \quad$ hot

nf nanofluid

$s \quad$ solid nanoparticles

\section{REFERENCES}

Abdelkader, S., Mebrouk, R., Abdellah, B., and Khadidja, B. 2007. "Natural Convection in a Horizontal Wavy Enclosure," Journal of Applied Sciences, 7(3), 334-341.

http://dx.doi.org/10.3923/jas.2007.334.341

Abu-Nada, E., and Oztop, H. F. 2011. "Numerical Analysis of A12O3/Water Nanofluids Natural Convection in a Wavy Walled Cavity," Numerical Heat Transfer, Part A: Applications, 59(5), 403-419.

http://dx.doi.org/10.1080/10407782.2011.552363

Barakos, G., Mitsoulis, E., and Assimacopoulos, D. 1994. "Natural Convection Flow in a Square Cavity Revisited: Laminar and Turbulent Models with Wall Functions," International Journal for Numerical Methods in Fluids, 18(7), 695-719. http://dx.doi.org/10.1002/fld.1650180705

Boulahia, Z., and Sehaqui, R. 2015. "Numerical Simulation of Natural
Convection of Nanofluid in a Square Cavity Including a Square Heater," International Journal of Science and Research (IJSR), 4(12), 1718-1722.

Boulahia, Z., Wakif, A., and Sehaqui, R. 2016. "Mixed Convection Heat Transfer of $\mathrm{Cu}$-Water Nanofluid in a Lid Driven Square Cavity with Several Heated Triangular Cylinders," International Journal of Innovation and Applied Studies, 17(1), 82-93.

Boulahia, Z., Wakif, A., and Sehaqui, R. 2016. "Natural Convection Heat Transfer of the nanofluids in a Square Enclosure with an Inside Cold Obstacle," International Journal of Innovation and Scientific Research, 21(2), 367-375.

Boulahia, Z., Wakif, A., and Sehaqui, R. 2016. "Numerical Investigation of Mixed Convection Heat Transfer of Nanofluid in a Lid Driven Square Cavity with Three Triangular Heating Blocks," International Journal of Computer Applications, 143(6), 37-45.

http://dx.doi.org/10.5120/ijca2016910227

Boulahia, Z., Wakif, A., and Sehaqui, R. 2016. "Numerical Study of Mixed Convection of the Nanofluids in Two-Sided Lid-Driven Square Cavity with a Pair of Triangular Heating Cylinders," Journal of Engineering, 2016.

http://dx.doi.org/10.1155/2016/8962091

Corcione, M. 2010. "Heat Transfer Features of Buoyancy-Driven Nanofluids inside Rectangular Enclosures Differentially Heated at the Sidewalls," International Journal of Thermal Sciences, 49(9), 15361546.

http://dx.doi.org/10.1016/j.ijthermalsci.2010.05.005

Corcione, M. 2011. "Empirical Correlating Equations for Predicting the Effective Thermal Conductivity and Dynamic Viscosity of Nanofluids," Energy Conversion and Management, 52(1), 789-793. http://dx.doi.org/10.1016/j.enconman.2010.06.072

Das, P. K., and Mahmud, S. 2003. "Numerical Investigation of Natural Convection inside a wavy enclosure," International Journal of Thermal Sciences, 42(4), 397-406. http://dx.doi.org/10.1016/S1290-0729(02)00040-6

De Vahl Davis, G. 1983. "Natural Convection of Air in a Square Cavity: a Bench mark Numerical Solution," International Journal for Numerical Methods in Fluids, 3(3), 249-264. http://dx.doi.org/10.1002/fld.1650030305

Dixit, H. N., and Babu, V. 2006. "Simulation of High Rayleigh Number Natural Convection in a Square Cavity Using the Lattice Boltzmann Method," International Journal of Heat and Mass Transfer, 49(3), 727 739.

http://dx.doi.org/10.1016/j.ijheatmasstransfer.2005.07.046

Haddad, Z., Oztop, H. F., Abu-Nada, E., and Mataoui, A. 2012. "A Review on Natural Convective Heat Transfer of Nanofluids," Renewable and Sustainable Energy Reviews, 16(7), 5363-5378.

http://dx.doi.org/10.1016/j.rser.2012.04.003

Incropera, F. P., and De Witt, D. P. 2002. Introduction to Heat Transfer (4th ed.). New York: Wiley.

Khanafer, K., Al-Azmi, B., Marafie, A., and Pop, I. 2009. "Non-Darcian Effects on Natural Convection Heat Transfer in a Wavy Porous Enclosure," International Journal of Heat and Mass Transfer, 52(7), 1887-1896. http://dx.doi.org/j.ijheatmasstransfer.2008.08.040

Mahmud, S., and Fraser, R. A. 2004. "Free Convection and Entropy 9 Generation inside a Vertical Inphase Wavy Cavity," International 
Communications in Heat and Mass Transfer, 31(4), 455-466. http://dx.doi.org/10.1016/S0735-1933(04)00027-2

Mahmud, S., and Fraser, R. A. 2007. "Visualizing Energy Flows through Energy Streamlines and Pathlines," International Journal of Heat and Mass Transfer, 50(19), 3990-4002.

http://dx.doi.org/10.1016/j.ijheatmasstransfer.2007.01.032

Mahmud, S., and Islam, A. K. M. S. 2003. "Laminar Free Convection and Entropy Generation inside an Inclined Wavy Enclosure," International Journal of Thermal Sciences, 42(11), 1003-1012. http://dx.doi.org/10.1016/S1290-0729(03)00076-0

Oztop, H. F., Abu-Nada, E., Varol, Y., and Chamkha, A. 2011. "Natural Convection in Wavy Enclosures with Volumetric Heat Sources," International Journal of Thermal Sciences, 50(4), 502-514. http://dx.doi.org/10.1016/j.ijthermalsci.2010.10.015
Patankar, S. 1980. Numerical Heat Transfer and Fluid Flow. McGrawHill, Washington: CRC press.

Spalding, D. B. 1972. "A Novel Finite Difference Formulation for Differential Expressions involving Both First and Second Derivatives," International Journal for Numerical Methods in Engineering, 4(4), 551559.

http://dx.doi.org/10.1002/nme.1620040409

Sultana, Z., and Hyder, M. N. 2007. "Non-Darcy Free Convection inside a Wavy Enclosure," International Communications in Heat and Mass Transfer, 34(2), 136-146.

http://dx.doi.org/10.1016/j.icheatmasstransfer.2006.10.007

Varol, Y., and Oztop, H. F. 2006. "Free Convection in a Shallow Wavy Enclosure," International Communications in Heat and Mass Transfer, 33(6), 764-771.

http://dx.doi.org/10.1016/j.icheatmasstransfer.2006.02.004 